\title{
A Pilot Study of Reference Vibrotactile Perception Thresholds on the Fingertip Obtained with Malaysian Healthy People Using ISO 13091-1 Equipment
}

\author{
Roshada DAUD ${ }^{1}$, Setsuo MAEDA ${ }^{2 *}$, Nur Nazmin Mustafa KAMEEL ${ }^{3}$, Muhamad Yunus RIPIN ${ }^{1}$, \\ Norazman BAKRUN ${ }^{1}$, Raemy MD ZEIN ${ }^{1}$, Masaharu KIDO ${ }^{4}$ and Kiyotaka HIGUCHI ${ }^{4}$ \\ ${ }^{1}$ Ergonomics Division, National Institute for Occupational Safety and Health, Lot 1, Jalan 15/1, Section 15, \\ 43650 Bandar Baru Bangl, Selangor Darul Ehsan, Malaysia \\ ${ }^{2}$ Department of Human Engineering, National Institute of Industrial Health, 21-1, Nagao 6-Chome, Tama-ku, \\ Kawasaki, Kanagawa 214-8585, Japan \\ ${ }^{3}$ Ergo Consult Sdn Bhd, No. 25-1, Jalan 3/4C, Desa Melawati, 53100 Kuala Lumpur, Malaysia \\ ${ }^{4}$ JICA Project, the Capacity Building of National Institute of Occupational Safety and Health, Lot 1, Jalan 15/1, \\ Section 15, 43650 Bandar Baru Bangl, Selangor Darul Ehsan, Malaysia
}

Received January 5, 2004 and accepted February 14, 2004

\begin{abstract}
The purpose of this paper is to clarify the reference vibrotactile perception thresholds (VPT) for healthy people in Malaysia. The measurement equipment standard, ISO 13091-1, of the vibrotactile perception thresholds for the assessment of nerve dysfunction and the analysis and interpretation of measurements at the fingertips standard, ISO 13091-2, were published in ISO/TC108/ SC4/WG8 on 2001 and 2003 individually. In the ISO 13091-2 standard, the reference VPT data were obtained from few research papers. Malaysian people's VPT data don't include to this standard. In Malaysia, when the VPT is using to diagnose of the hand-arm vibration syndrome, the reference VPT data need to compare with the worker's ones. But, Malaysia does not have the reference VPT data yet. So, in this paper, the VPT was measured by using ISO 13091-1 standard equipment to obtain the reference data for Malaysian people. And these data were compared with the ISO reference data on the ISO 13091-2 standard. From the comparison of these data, it was clear that the Malaysian healthy people's VPT data were consistent with the reference data of the ISO 13091-2 standard.
\end{abstract}

Key words: Vibrotactile perception thresholds, Hand-arm vibration, ISO 13091-1, ISO 13091-2, Diagnosis, Vibration

\section{Introduction}

Occupational exposures to hand-transmitted vibration cause a variety of disorders of the fingers, hand, and arms. These include neurological disturbances and vascular disorders (sometimes called Raynaud's phenomenon or vibration-induced white finger $)^{1}$.

Fingertip vibrotactile thresholds have been used to quantify the neuropathy produced by hand-transmitted vibration ${ }^{2-6}$.

\footnotetext{
*To whom correspondence should be addressed.
}

Vibrotactile thresholds have also been used to estimate the acute physiological effects of hand-transmitted vibration exposure on the sensory system and investigate a permissible limit for occupational exposure to vibration. Many studies have related the temporary threshold shifts (TTS) in vibratory sensation to the severity of vibration exposure ${ }^{7-18}$. Vibration sense thresholds at the fingertips are sometimes used to evaluate the neuropathy, and the vibrotactile thresholds on the fingers are known to depend on these specifies, measuring equipments, procedure, and method or algorithm ${ }^{19-24)}$. Researchers around the world have used many different types 
of vibrotactile measurement equipment. Since 1991 the working group 8 (Vibrotactile Perception) of ISO/TC108/ $\mathrm{SC} 4$ has been involved in optimizing testing procedures and interpreting vibrotactile perception thresholds. The vibrotactile perception thresholds measurement equipment standard, ISO 13091-125), was published in ISO/TC108/SC4/ WG8 on 2001. And also, the vibrotactile perception thresholds for the assessment of nerve dysfunction for analysis and interpretation of measurements at the fingertips standard, ISO 13091-2 ${ }^{26)}$, was published on 2003. In the ISO 13091-2 standard, the reference VPT data were obtained from few research papers. But, Malaysian people's VPT data don't include to this standard.

The main objective of this study is to measure the fingertip vibrotactile thresholds as to get reference data for the Malaysian people. This study also is to find a comparison of vibrotactile perception thresholds for male and female. The findings of this study for healthy people will then compared to ISO 13091-2 by implementation of ISO equipment.

In Malaysia, the study that related to occupational exposures to hand-transmitted vibration had not been carried out and this study can be a platform for other study to get a reference data.

\section{Experiment}

\section{Equipment specification}

The computer driven HVLab tactile vibrometer developed at the University of Southampton's Institute of Sound and Vibration Research and Human Factors Research Unit. The vibrometer unit housed a vibrator, which was mounted on a counter balance, so as to provide a constant upward force of contact between the probe and the subject's finger as shown in Fig. 1.

A sliding counter-weight allowed this force to be adjusted if required. A locking mechanism for the balance is provided to protect the equipment from damage in transit. An accelerometer was mounted on the vibrator, with the contact probe attached to its upper surface. The probe, which had a flat circular end of $6 \mathrm{~mm}$ diameter, protruded through a circular hole of $10 \mathrm{~mm}$ diameter in a Perspex plate mounted in the top cover of the vibrometer unit. This plate was pitter strain gauges to monitor and control the push force from the finger. The vibrometer unit housed the electronic for conditioning the accelerometer and strain gauge output signals and the power amplifier for driving the vibrator.

During the measurement of the vibrotactile threshold, the magnitude of the vibration is automatically increased until

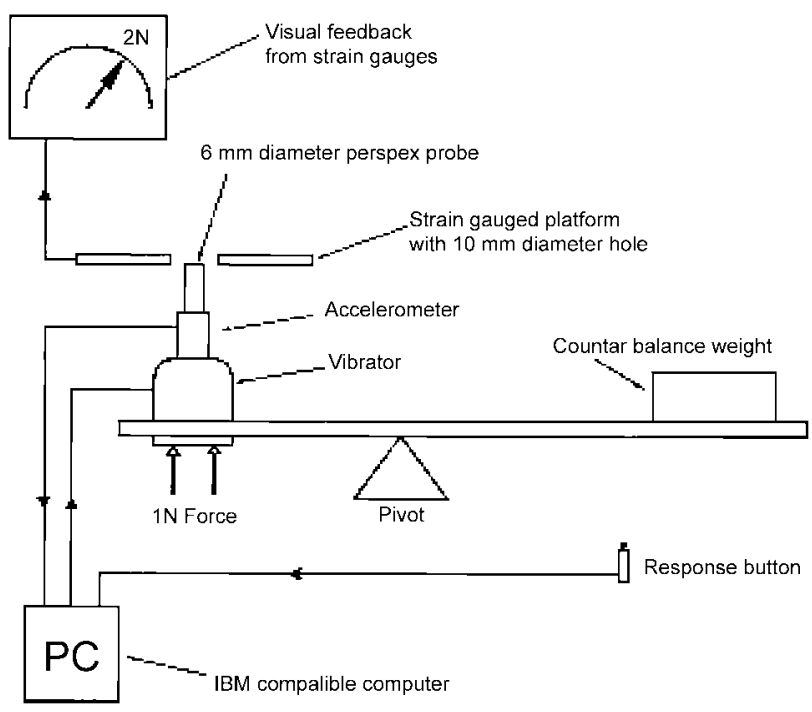

Fig. 1. Vibrotactile measurement equipment (ISO-type equipment).

the subject presses the response button. The magnitude is then decreased until the button is released. The process is repeated several times to establish a threshold level for perception of vibration by a similar method to that used in automatic recording audiometers (the Bekesy method). A pre-determined set of selected vibration frequencies (in the range 16 to $500 \mathrm{~Hz}$ ) is automatically presented.

The acceleration magnitude corresponding to the vibrotactile threshold at each frequency is computed at the end of each test using procedure defined in BS 6655 (British Standard Institution 1986) ${ }^{27)}$ and ISO 6189 (International Organization for Standardization 1983 ${ }^{28)}$. First, the peaks (the vibration magnitudes when the response button is pressed) and then through (the magnitude when the button is released) are average separately. The vibrotactile threshold is then taken as the mean of the average peak and the average through. Warning are given if any of the following conditions apply: (1) there are less than 6 reversals (i.e., button presses and releases; the first reversal at every frequency is ignored); (2) the peaks deviate by more than $10 \mathrm{~dB}$ among themselves; and (3) the troughs deviate by more than $10 \mathrm{~dB}$ among themselves. Standard deviations are also computed, from the square root of the mean variance of the peaks and troughs. A vibrogram, showing the acceleration magnitude at each reversal as a function of time may be viewed on the screen or output to a printer. The system is controlled by an IBM $\mathrm{PC}$ compatible computer, which generates the vibration signals to drive the vibrator, monitors the vibration magnitude and the response button and computes the threshold values. As shown in Table 1, the ISO 13091-1 standard defines the 
Table 1. Measurement conditions of the ISO 13091-1 standard equipment

\begin{tabular}{llll}
\hline \multicolumn{1}{c}{ Contents } & \multicolumn{3}{c}{ ISO 13091-1 } \\
\hline Mechanoreceptor & SAI, & FAI, & FAII \\
Frequency $(\mathrm{Hz})$ & 4.0, & 31.5, & 125 \\
Other frequencies $(\mathrm{Hz})$ & $3.15 ; 5.0$ & $20 ; 25$ & $100 ; 160$ \\
Subject support & full length of forearm, hand and finger; seat with back rest \\
Skin temperature & $27-36^{\circ} \mathrm{C}$ & \\
Test room temperature & $20-30^{\circ} \mathrm{C}$ & \\
Probe tip geometry & flat-ended cylinder, $0.2 \mathrm{~mm}<$ edges radii < $0.7 \mathrm{~mm}$ \\
& Smooth to touch \\
Probe tip diameter & $4.0 \mathrm{~mm} \pm 2.1$ mm diameter \\
Skin-stimulator contact & No Surround - Method A & Surround - Method B \\
Skin indentation & $1.5 \pm 0.8 \mathrm{~mm}$ & $1.5 \pm 0.8 \mathrm{~mm}$ \\
Probe-surround gap & \multicolumn{2}{c}{$0.5 \pm 0.6 \mathrm{~mm}$} \\
Surround force & \multicolumn{2}{c}{$0.7 \mathrm{~N}$ to $2.3 \mathrm{~N}$} \\
Measurement algorithm & variant of up-down, or von Bekesy \\
Vibration measurement & r.m.s. magnitude and frequency of stimuli \\
\hline
\end{tabular}

Table 2. Experimental condition of Method B used in this experiment

\begin{tabular}{ll}
\hline Vibration frequency & $31.5 \mathrm{~Hz}$ and $125 \mathrm{~Hz}$ \\
Contact area & $6 \mathrm{~mm}$ diameter $\left(28 \mathrm{~mm}^{2}\right)$ \\
Surrounding & $10 \mathrm{~mm}$ \\
Finger push force & $2 \mathrm{~N}$ \\
Probe contact force & $1 \mathrm{~N}$ \\
Measuring finger & The index finger of right-hand \\
Each frequency test time & $30 \mathrm{~s}$ \\
Measuring method & Bekesy method \\
Level rate & $3 \mathrm{~dB} / \mathrm{s}$ \\
Room temperature & $22-26^{\circ} \mathrm{C}$ \\
Finger skin temperature & Above $23^{\circ} \mathrm{C}$ \\
\hline
\end{tabular}

requirements for measurement conditions to measure the vibrotactile perception thresholds.

\section{Experimental conditions}

To measure the vibrotactile thresholds using ISO 130911 standard equipment, Table 2 shows the used experimental conditions in this experiment.

In this experiment, two different frequencies of vibrotactile stimulation were selected for preferential activation of separate afferent classes, $31.5 \mathrm{~Hz}$ to preferentially activate fast adapting I (FA I) units and $125 \mathrm{~Hz}$ to activate the fast adapting II (FA II) as Pacinian units.

\section{Subjects}

Thirty-two subjects ( 8 males and 24 females) age 22 to 51 participated in this study. The mean age and standard deviation (SD) for males and female is $28.1 \mathrm{yr}$ (SD $3.23 \mathrm{yr}$ )
Table 3. Physical characteristic of the subjects in this experiment

\begin{tabular}{lcccc}
\hline & $\begin{array}{c}\text { Subject } \\
\text { Number (n) }\end{array}$ & $\begin{array}{c}\text { Age (yr) } \\
\text { Mean (SD) }\end{array}$ & $\begin{array}{c}\text { Weight (kg) } \\
\text { Mean (SD) }\end{array}$ & $\begin{array}{c}\text { Height (m) } \\
\text { Mean (SD) }\end{array}$ \\
\hline Male & 8 & $28.1(3.23)$ & $66.27(13.71)$ & $167.4(7.16)$ \\
Female & 24 & $31.7(7.32)$ & $55.94(12.15)$ & $153.8(3.83)$ \\
\hline
\end{tabular}

and $31.7 \mathrm{yr}$ (SD $7.32 \mathrm{yr}$ ) respectively. All subjects are a healthy people and having no history of neuromuscular or vascular disorders. None of them had prior occupational experience operating powered hand tools or had suffered any serious injuries in upper extremity. Table 3 shows other subject body characteristics.

\section{Procedure}

The instruction sheet shown in Appendix A was presented to the subject before measuring the data. Room temperature was held in the range 22 to $26^{\circ} \mathrm{C}$. First, the right-hand finger temperature was measured because it is known that skin temperature will affect vibrotactile thresholds ${ }^{3)}$. The experiment was performed only when the finger temperature was above $23^{\circ} \mathrm{C}$.

Each subject was seated with the right forearm laid on an armrest and put the index finger on the right hand on the vibration tip. The subjects have to watch a meter carefully to maintain his push force to the appointed level $(2 \mathrm{~N})$. Then the technician will start to measure and for the first time the subject will do a practical test to make them clear with the vibration that will appear at the fingertips. After they are familiar with the vibration, the technician will do the actual 

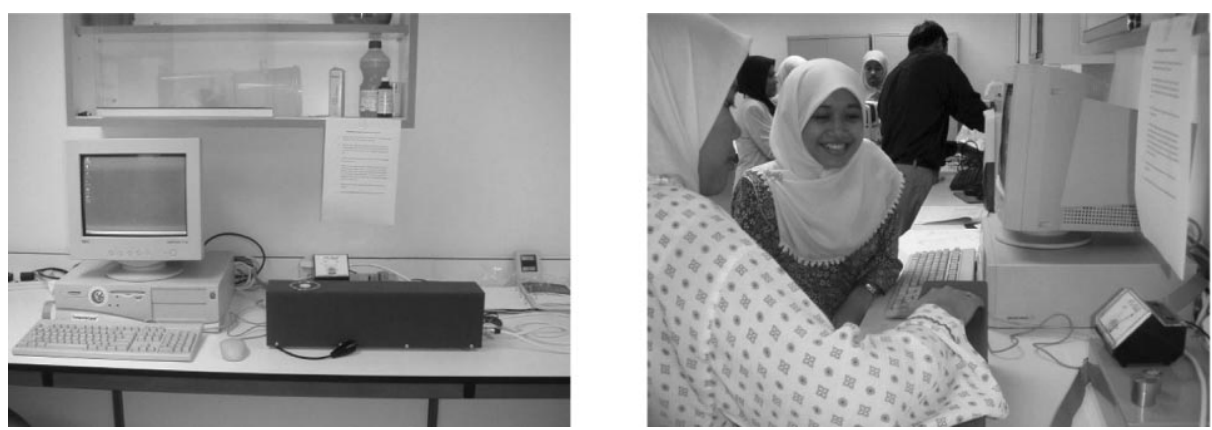

Fig. 2. Real experimental scene at Ergonomics Division of NIOSH in Malaysia.

Table 4. 50 percentile of vibrotactile perception thresholds for healthy Malaysian persons expressed in metres per second squared of the current results

\begin{tabular}{lccc}
\hline Gender & Age yr (SD) & Mean 31.5 Hz (SD) & Mean 125 Hz (SD) \\
\hline Males & $28.1(3.2)$ & $0.134(0.065)$ & $0.228(0.09)$ \\
Females & $31.5(7.4)$ & $0.132(0.098)$ & $0.364(0.413)$ \\
\hline
\end{tabular}

test and take about $30 \mathrm{~s}$. Figure 2 shows the HVLab tactile vibrometer and the real measurement at Ergonomics Division of NIOSH in Malaysia.

\section{Analytical Methods}

For each group of subjects, group means and standard errors were calculated for the detection threshold of each test frequency at the right-hand index fingertip. To analyze the effects of gender, frequency, and age on vibrotactile thresholds, a three way ANOVA with repeated measures, formatted as $\mathrm{A} \times \mathrm{B} \times \mathrm{C}$ with repeated measures on variables $\mathrm{B}$ and $\mathrm{C}$, was used to analyze all the data. Variable A defined as gender, $\mathrm{B}$ was defined as frequency and variable $\mathrm{C}$ was defined as age. The Reference Data of ISO 13091-2 were assumed to be the mean value from a certain population, and in order to investigate whether there is any difference in mean value; $\mathrm{t}$ test for a single sample was performed.

\section{Results and Discussion}

Table 4 shows the mean threshold results and standard deviations obtained from males and females at $31.5 \mathrm{~Hz}$ and $125 \mathrm{~Hz}$. The mean vibrotactile perception threshold data of both genders at $31.5 \mathrm{~Hz}$ are smaller than ones at $125 \mathrm{~Hz}$. The standard deviation data on females at $125 \mathrm{~Hz}$ are greater than ones at $31.5 \mathrm{~Hz}$. It may be thought that the standard deviation of age on female is depending on the high deviation.
Table 5. 50 percentile of vibrotactile perception thresholds for healthy persons expressed in metres per second squared of the ISO 13091-2 standard

\begin{tabular}{lccc}
\hline Gender & Age yr & VPT $(31.5 \mathrm{~Hz})$ & VPT $(125 \mathrm{~Hz})$ \\
\hline Males & 30 & 0.10 & 0.25 \\
Females & 30 & 0.12 & 0.32 \\
\hline
\end{tabular}

These results conform to previous observations on frequency ${ }^{19)}$, age and gender ${ }^{29}$. From the current results, ANOVA revealed statistically significant main effects for frequency $(\mathrm{F}=20.171, \mathrm{p}=0.002)$, for age $(\mathrm{F}=3.129, \mathrm{p}=0.043)$ and for gender $(\mathrm{F}=10.633, \mathrm{p}=0.010)$.

And these data were compared with the ISO reference data at $31.5 \mathrm{~Hz}$ and $125 \mathrm{~Hz}$ as shown in Table 5 on the ISO 13091-2 standard.

In order to investigate whether there is any difference in Reference Data of ISO 13091-2, and the mean value of the VPT data obtained in the current experiment, Reference Data of ISO 13091-2 was assumed to be the mean value from a certain population, and test for a single sample was performed between these experiment data. Consequently, in all data, the hypothesis was not rejected with the significant level $\alpha=0.05$. Therefore, it became clear that there is no difference in mean value between Reference Data of ISO 13091-2 and these current experiment data.

The overall results of the current study are in agreement with the vibrotactile perception data of the ISO 13091-2 standard.

\section{Conclusions}

In this paper, the VPT was measured by using ISO 130911 standard equipment to obtain the reference date for Malaysian people. From the comparison of these data as a pilot study, it was clear that the Malaysian healthy people's 
vibrotactile perception threshold data at $31.5 \mathrm{~Hz}$ and 125 $\mathrm{Hz}$ were consistent with the reference data of the ISO 130912 standard.

In Malaysia, the study that related to occupational exposures to hand-transmitted vibration had not been carried out and this study can be a platform for other study to get a reference data.

\section{Acknowledgement}

This study was supported by NIOSH-JICA project of JICA. We would like to thank all NIOSH, DOSH and JICA staff in Malaysia who took part in this research.

\section{References}

1) Griffin MJ (1990) Handbook of human vibration. Academic Press, London.

2) Brammer AJ (1987) Assessment of impaired tactile sensation. Scand J Work Environ Health 13, 380-4.

3) Hayward R, Griffin MJ (1986) Measures of vibrotactile sensitivity in persons exposed to hand-arm vibration. Scand J Work Environ Health 12, 423-7.

4) Jezter T, Conrad H, Heithoff K (1987) The role of CT scanning and vibrometry testing in the diagnostic evaluation of carpal tunnel syndrome. In: Proceedings of Volvo-IFSSH Conference on the prevention of brachial injuries and cumulative trauma disorders, 537, Stockholm.

5) Lundborg G, Lie-Stenstrom AK, Sollerman C, Stromberg T, Pyykko I (1986) Digital vibrogram: a new diagnostic tool for sensory testing in comparison neuropathy. Hand Surg 11A, 693-9.

6) Lundborg G, Sollerman C, Stromberg T, Pyykko I, Rosen B (1987) A new principle for assessing vibrotactile sense in vibration-induced neuropathy. Scand J Work Environ Health 13, 375-9.

7) Harada N (1978a) Studies on the changes in the vibratory sensation threshold at the fingertip in elation to some physical parameters of exposed vibration, Part 1, a study on the methods of vibration exposure and measurement of the vibratory sensation threshold. Jpa J Hyg 33, 699705.

8) Harada N (1978b) Studies on the changes in the vibratory sensation threshold at the fingertip in elation to some physical parameters of exposed vibration, Part 2, a study on the equal TTS curves of the vibratory sensation and the hygienic allowable limit of portable mechanized tool. Jpn J Hyg 33, 706-17.
9) Harada N, Griffin MJ (1991) Factors influencing vibration sense thresholds used to assess occupational exposure to hand-transmitted vibration. Brit J Ind Med 48, 185-92.

10) Hayward R (1984) Temporary threshold shifts in vibrotactile sensitivity: effects of vibration duration, intensity, and frequency. In: Proceedings of U.K. informal group meeting on human response to vibration, 36-46, Heriot-Watt University, Edinburgh.

11) Maeda S (1991) Comparison of the effects of handtransmitted continuous vibration and shock vibration on temporary threshold shifts in fingertip vibratory sensation. In: Proceedings of the Anglo-French vibration meeting and the United Kingdom informal group meeting on human response to vibration, $40-56$, H.S.E., Buxton.

12) Maeda $S$, Kume $Y$ (1987) Temporary threshold shift on finger-tip vibratory sensation induced by exposure to octave band vibration. J Jpn Ind Manage Associ 38, 243-8.

13) Maeda S, Kume Y (1989) Temporary threshold shift on finger-tip vibratory sensation induced by exposure to spectrum vibration. J Jpn Ind Manage Associ 40, $336-42$.

14) Maeda S, Kume Y (1991) Temporary threshold shift on finger-tip vibratory sensation induced by exposure to intermittent vibration (on the exposure-equivalent rule). J Jpn Ind Manage Associ 42, 105-11.

15) Malinskaya NN, Filin AP, Shkarinov LN (1964) Problem of occupational hygiene in operating mechanical tools. Vestnik Academy Med Sci USSR 19, 31-6.

16) Nishiyama K, Watanabe $S$ (1981) Temporary threshold shift of vibratory sensation after clasping a vibrating handle. Int Arc Occup Environ Health 49, 21-3.

17) Radzyukevich TM (1969) Interrelation of temporary and permanent shifts of vibration and pain sensitivity threshold under the effect of local vibration. Gigiena Truda I Professional'nye Zabolevanija 14, 20-3.

18) Taoda K (1991) Temporary threshold shift of vibratory sensation (TTSv) induced by the composite band vibration exposure. J Shiga Univ Med Sci 6, 117-26.

19) Maeda S, Griffin MJ (1994) A comparison of vibrotactile thresholds on the finger obtained with difference equipment. Ergonomics 37, 1391-406.

20) Maeda $S$ (1991) A comparison of measuring equipment and measuring algorithm for vibrotactile thresholds on the fingers. In: Proceedings of the United Kingdom Informal Group Meeting on Human Response to 
Vibration. ISVR, Southampton, England.

21) Maeda $S$ (1994) A comparison of vibration acceleration magnitude obtained with different vibrotactile threshold measuring equipment. In: Proceedings of the Japan Informal Group Meeting on Human Response to Vibration. NIIH, Kawasaki, Japan.

22) Maeda S, Morioka M, Yonekawa Y, Kanada K, Takahashi Y (1997) A comparison of vibrotactile thresholds on the finger obtained with ISO type equipment and Japanese equipment. Industrial Health 35, 343-52.

23) Maeda S, Griffin MJ (1995) A comparison of vibrotactile thresholds on the finger obtained with different algorithms. Arbete och Halsa 5, 85-95.

24) Lindsell CJ (1997) Vibrotactile thresholds: effects of contact forces and skin indentation. In: Proceedings of the United Kingdom Informal Group Meeting on Human Response to Vibration. ISVR, Southampton, England.

25) International Organization for Standardization (2001)
Mechanical vibration-Vibroactile perception thresholds for the assessment of nerve dysfunctionPart 1: Methods of measurement at the fingertips, ISO 13091-1.

26) International Organization for Standardization (2003) Mechanical vibration-Vibroactile perception thresholds for the assessment of nerve dysfunctionPart 2: Analysis and interpretation of measurements at the fingertips, ISO 13091-2.

27) British Standards Institution (1986) British Standard Specification for pure tone air conduction threshold audiometry for hearing conservation purposes, BS 6655.

28) International Organization for Standardization (1983) Acoustics-Pure tone air conduction threshold audiometry for hearing conservation purposes, ISO 6189.

29) Wild P, Massin N, Lasfargues G, Baudin V, Unlu D, Donati P (2001) Vibrotactile perception thresholds in four non-exposed populations of working age. Ergonomics 44, 649-57. 


\section{Appendix - Instructions for subjects}

\section{Vibrotactile perception threshold measurement}

1. Rest your arm on the vibrometer so that the center of the whorl on your fingertip is situated over the center of the probe.

2. Watch the force feedback unit and press down gently on the probe until the needle reaches the 'ON' position. Keep the pressure on the probe so that the needle remains in the 'ON' position throughout the test.

3. Hold the respond button unit in the opposite hand with the thumb over the response button.
4. When you feel a vibration sensation at the probe, press the response button and keep it pressed until you can no longer feel the vibration. When the vibration can no longer be felt, release the response button until the vibration sensation is felt again (i.e. when you can feel the vibration, the button should be down, when you can't feel the vibration, the button should be up).

5. Repeat this cycle until the experimenter informs you that the test is complete.

6. Please ask technician should you need further assistant/ explanation. 